mediastudies.press • Social Media \& the Self: An Open Reader

\title{
The Genesis of the Self
}

George Herbert Mead

Published on: Apr 01,1925

License: Creative Commons Public Domain Dedication (CC-0 4.0). 
THE SELF THAT is central to all so-called mental experience has appeared only in the social conduct of human vertebrates. It is just because the individual finds himself taking the attitudes of the others who are involved in his conduct that he becomes an object for himself. It is only by taking the rôles of others that we have been able to come back to ourselves. [...]

It is interesting to note that in the development of the individual child, there are two stages which present the two essential steps in attaining self-consciousness. The first stage is that of play, and the second that of the game, where these two are distinguished from each other. In play in this sense, the child is continually acting as a parent, a teacher, a preacher, a grocery man, a policeman, a pirate, or an Indian. It is the period of childish existence which Wordsworth has described as that of "endless imitation." It is the period of Froebel's kindergarten plays. In it, as Froebel recognized, the child is acquiring the rôles of those who belong to his society. This takes place because the child is continually exciting in himself the responses to his own social acts. In his infant dependence upon the responses of others to his own social stimuli, he is peculiarly sensitive to this relation. Having in his own nature the beginning of the parental response, he calls it out by his own appeals. The doll is the universal type of this, but before he plays with a doll, he responds in tone of voice and in attitude as his parents respond to his own cries and chortles. [...] That is, one calls or tends to call out in himself the same response that he calls out in the other.

The play antedates the game. For in a game there is a regulated procedure, and rules. The child must not only take the rôle of the other, as he does in the play, but he must assume the various rôles of all the participants in the game, and govern his action accordingly. If he plays first base, it is as the one to whom the ball will be thrown from the field or from the catcher. Their organized reactions to him he has imbedded in his own playing of the different positions, and this organized reaction becomes what I have called the "generalized other" that accompanies and controls his conduct. And it is this generalized other in his experience which provides him with a self.

We are in possession of selves just in so far as we can and do take the attitudes of others toward ourselves and respond to those attitudes. We approve of ourselves and condemn ourselves. We pat ourselves upon the back and in blind fury attack ourselves. We assume the generalized attitude of the group, in the censor that stands at the door of our imagery and inner conversations, and in the affirmation of the laws and axioms 
of the universe of discourse. Quod semper, quod ubique. Our thinking is an inner conversation in which we may be taking the rôles of specific acquaintances over against ourselves, but usually it is with what I have termed the "generalized other" that we converse, and so attain to the levels of abstract thinking, and that impersonality, that so-called objectivity that we cherish.

One assumes, as I have said, the attitudes of generalized others. But even with this advantage of the universal over the multiplicity of its numberless instances, the number of different responses that enter into our social conduct seems to defy any capacity of any individual to assume the rôles which would be essential to define our social objects. And yet, though modern life has become indefinitely more complex than it was in earlier periods of human history, it is far easier for the modern man than for his predecessor to put himself in the place of those who contribute to his necessities, who share with him the functions of government, or join with him in determining prices. It is not the number of participants, or even the number of different functions, that is of primary importance. The important question is whether these various forms of activities belong so naturally to the member of a human society that, in taking the role of another, his activities are found to belong to one's own nature. As long as the complexities of human society do not exceed those of the central nervous system, the problem of an adequate social object, which is identical with that of an adequate selfconsciousness, is not that of becoming acquainted with the indefinite number of acts that are involved in social behavior, but that of so overcoming the distances in space and time, and the barriers of language and convention and social status, that we can converse with ourselves in the rôles of those who are involved with us in the common undertaking of life. A journalism that is insatiably curious about the human attitudes of all of us is the sign of the times. The other curiosities as to the conditions under which other people live, and work, and fight each other, and love each other, follow from the fundamental curiosity which is the passion of self-consciousness. We must be others if we are to be ourselves.

\section{EXCERPT}

"The Genesis of the Self and Social Control" (George Herbert Mead, International Journal of Ethics 35, no. 3 (1925): 268, 269, 272, 275-76)

PUBLIC DOMAIN 